\section{Acral pityriasis rosea: A rare variant of pityriasis rosea}

\section{Pimpa Tantanasrigul, Mingkwan \\ Wichaidit, Preya Kullavanijaya}

Institute of Dermatology, Ministry of Public Health, Thailand

\section{Letter}

Pityriasis rosea (PR) is a common, selflimited inflammatory skin condition, usually affects the trunk and proximal extremities. A variety of atypical manifestations of PR have been recognized ranging from the difference in the morphology, distribution, and course. Herein, the rare form of acral PR in an adult has been illustrated as the 29year-old Thai female who presented with generalized erythematous papules and plaques with peripheral collarette scales on the trunk and extremities, prominently on the hands and feet (Figures 1-3). The face and mucous membranes were spared. The patient denied associated systemic symptoms such as fever. There was no history of genital ulceration. The provisional diagnosis of PR was initially made due to the presence of fine collarette scales, the oval morphology of the lesions, and the Christmastree distribution. Secondary syphilis, erythema annulare centrifugum and psoriasis were also considered as the differential diagnoses.

The rapid plasma reagin (RPR) and treponema pallidum particle agglutination (TPPA) assays were both negative. Blood test for anti-HIV was not collected.
Histopathology showed spongiotic dermatitis with lymphocytes. Superficial perivascular infiltration with lymphocytes and extravasation of red blood cells were observed without an evidence of plasma cell (Figure 4). Hyperkeratosis and parakeratosis were also noted. All histologic findings supported the diagnosis of PR. Despite the treatment with moderate potency topical corticosteroids and the four-week course of oral roxithromycin, the disease continued to progress. A short course of oral prednisolone $(0.5 \mathrm{mg} / \mathrm{kg} /$ day $)$ was added which finally led to a complete resolution. There was no recurrence on the 3-month followed-up period

Acral, or palmoplantar, PR can affect patients of all ages but there have been more reports in adults. The morphology of acral PR varied from scaly plaques to vesicles, however, the latter were usually categorized as vesicular PR variant. Although acral PR had been defined as primary and secondary eruptions confined to the acral parts, the rash on the other locations, e.g. the trunk and distal extremities, usually coexist. ${ }^{1}$ To date, there have been less than ten published cases of acral PR in English literature. ${ }^{1-5}$ It is difficult to delineate the clinical pattern of acral PR due to an insufficient number of cases. In general, acral PR would be diagnosed when the palmoplantar areas were involved where the rash can either limited to the acral sites or extended beyond the palms or soles. The management of acral PR was identical to those of the classic disease. The course and prognosis were unaffected in this variant.

Criteria for diagnosis of PR were proposed by Chuh et al. ${ }^{1}$ comprised three

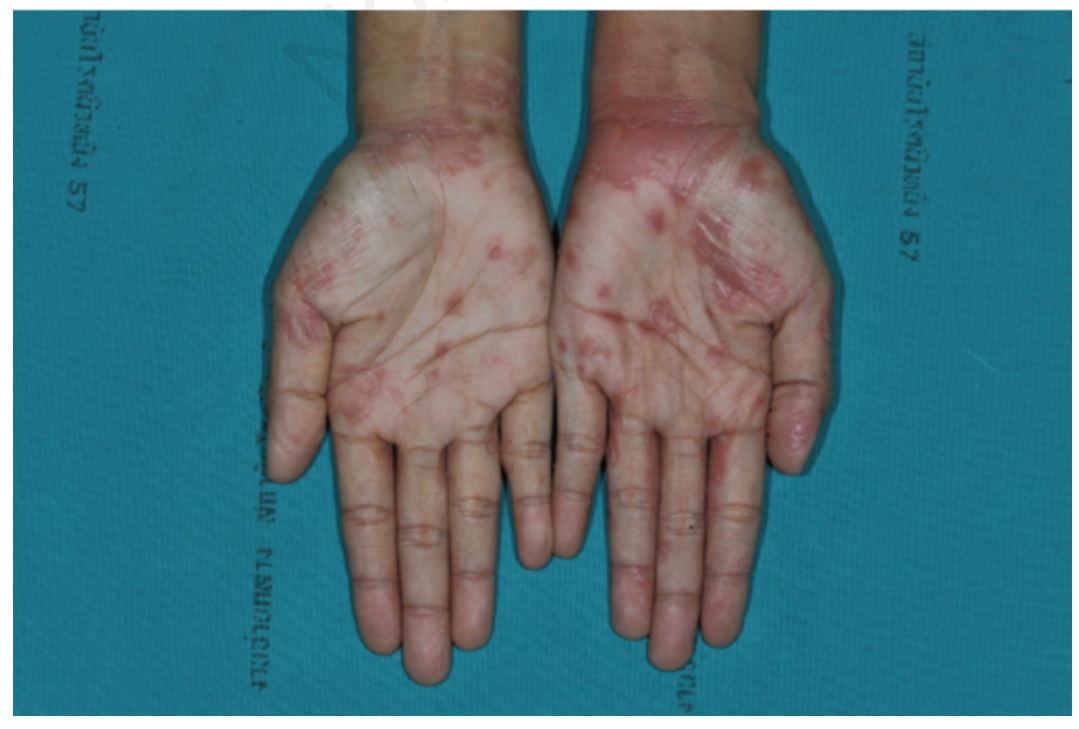

Figure 1. Typical erythematous papules with collarette scales on the palms.
Correspondence: Pimpa Tantanasrigul, Institute of Dermatology, Ministry of Public Health, 420/7 Ratchawithi Rd, Thung Phaya Thai, Ratchathewi, Bangkok, 10400 Thailand. Tel.: +66.0-2354-5222.

E-mail: pimpa.tantanasrigul@gmail.com

Key words: Pityriasis rosea; acral; palmoplantar; atypical.

Contributions: The authors contributed equally.

Conflict of interest: The authors declare no potential conflict of interest.

Acknowledgments: The authors would thank Dr. Poonnawis Sudtikoonaseth, MD. as a dermatopathologist.

Funding: None.

Please cite this article as: Tantanasrigul $P$, Wichaidit M, Kullavanijaya P. Acral pityriasis rosea: A rare variant of pityriasis rosea. Dermatol Rep 2021;13:9081.

Received for publication: 23 January 2021. Revision received: 12 February 2021. Accepted for publication: 9 March 2021.

This work is licensed under a Creative Commons Attribution-NonCommercial 4.0 International License (CC BY-NC 4.0).

${ }^{\circ}$ Copyright: the Author(s), 2021

Licensee PAGEPress, Italy

Dermatology Reports 2021; 13:9081

doi:10.4081/dr.2021.9081

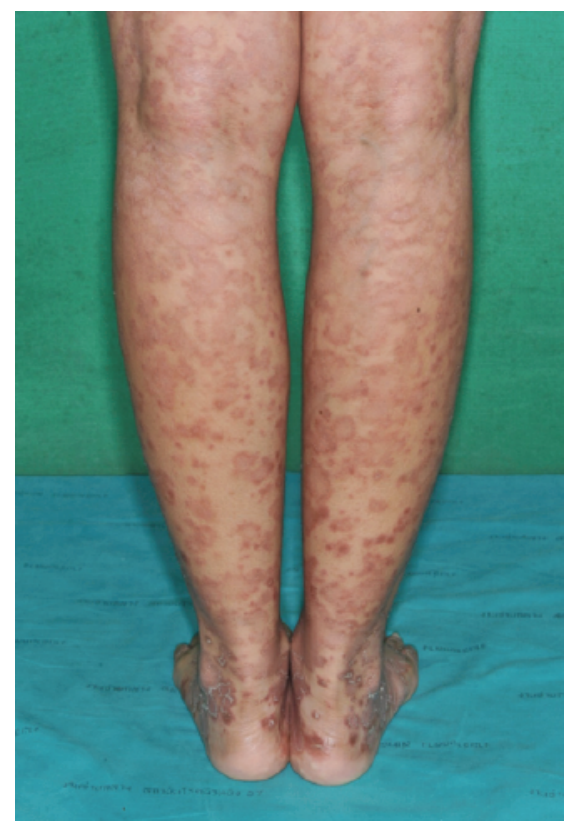

Figure 2. The generalized eruption was evidenced on the entire legs.with collarette scales on the palms. 
major components as follows; the "essential", "optional", and "exclusional" clinical characteristics. The diagnosis of PR would be established by fulfilling all the essential features plus at least one of the optional features. In brief, the "essential" clinical presentation for PR must include scaly circular eruptions with two lesions at the minimum showing peripheral collarette scale plus at least one of these following "optional" features; (i) truncal and proximal extremities involvement with less than $10 \%$ of lesions on the distal limbs, (ii) most lesions distribute along the ribs, and (iii) the presence of a herald patch. Pityriasis rosea would be unlikely if any "exclusional" features present including multiple vesicular lesions, predominant palmoplantar distribution, and clinical or serological tests indicate secondary syphilis. These criteria seem to be

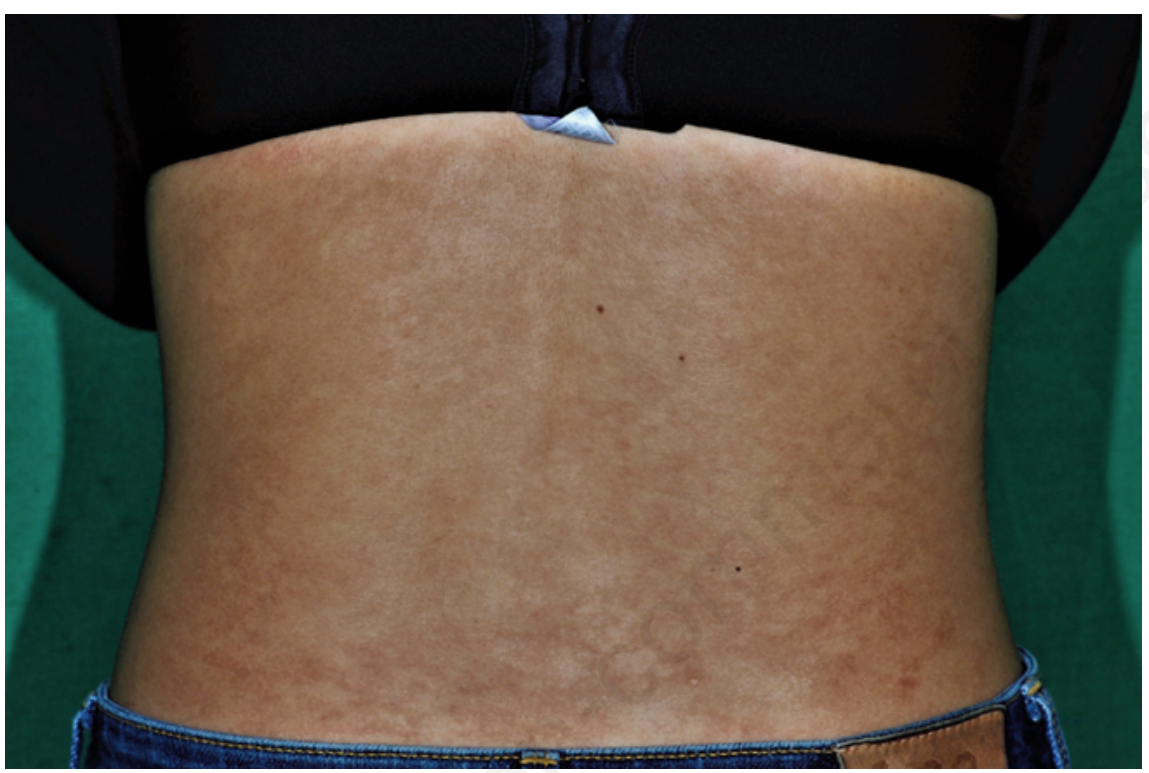

Figure 3. The rash distributed along cleavage lines of the back or a "Christmas tree" distribution.

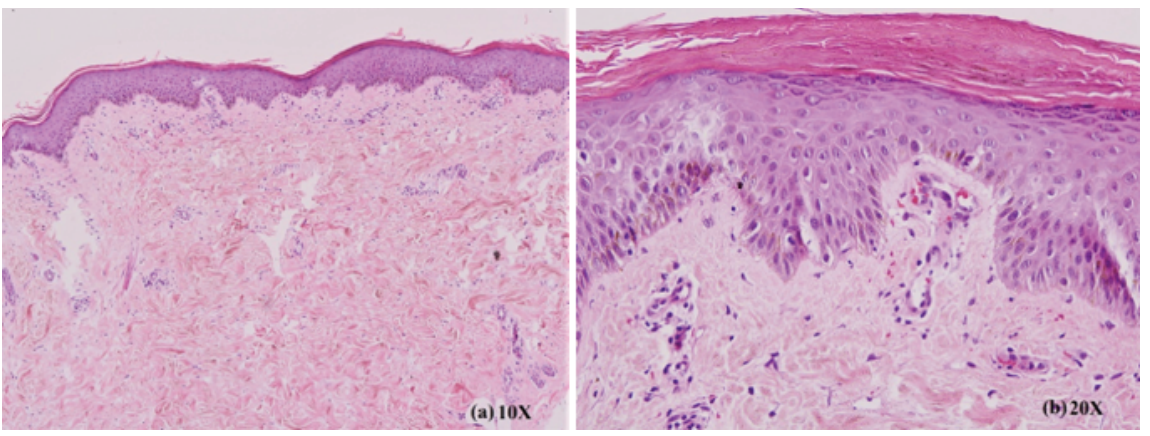

Figure 4. a) The section displayed mild acanthotic epidermis with hyperkeratosis and focal parakeratosis. There was superficial perivascular infiltration on the upper dermis. b) Lymphocytic infiltration and extravasation of red blood cells were evident. (Hematoxylin and eosin stain). applicable for typical PR but not for other atypical forms since the exclusion criteria would ultimately rule out certain types of atypical PR such as acral and vesicular varidiagnostic criteria to minimize the potential of the underdiagnosis of some atypical PR subsets.

In summary, acral PR accompanied by the typical PR eruptions distributed in a disseminated pattern was reported. The existed criteria may facilitate the diagnosis of classic PR but fail to diagnose acral PR. The strong clinical clue for acral PR is the presence of collarette scales within the periphobserved either on the palmoplantar surfaces or other locations. Herald patch is also pathognomonic that can be generally observed in up to $80 \%$ of PR cases while ants. It is thus crucial to revise the above ery of typical PR lesions which could be palmoplantar herald patches were reported in a few patients. ${ }^{4-7}$ As the appearance of palmoplantar lesions may indicate secondary syphilis, serological tests should always be investigated in virtually all suspected cases.

\section{References}

1. Chuh AA. Diagnostic criteria for pityriasis rosea: a prospective case control study for assessment of validity. JEADV 2003;17:101-3.

2. Deng Y, Li H, Chen X. Palmoplantar pityriasis rosea: two case reports. JEADV 2007;21:406-7.

3. Bukhari I. Pityriasis rosea with palmoplantar plaque lesions. Dermatol Online J 2005:11.

4. Polat M, Yildirim Y, Makara A. Palmar herald patch in pityriasis rosea. Australas J Dermatol 2012;53:e64-5.

5. Robati RM, Toossi P. Plantar herald patch in pityriasis rosea. Clin Exper Dermatol 2009;34:269-70.

6. Gonzalez LM, Allen R, Janniger CK, Schwartz RA. Pityriasis rosea: an important papulosquamous disorder. Int J Dermatol 2005;44:757-64.

7. Ozyurek GD, Alan S, Cenesizoglu E. Evaluation of clinico-epidemiological and histopathological features of pityriasis rosea. Postepy Dermatologii i Alergologii 2014;31:216-21. 